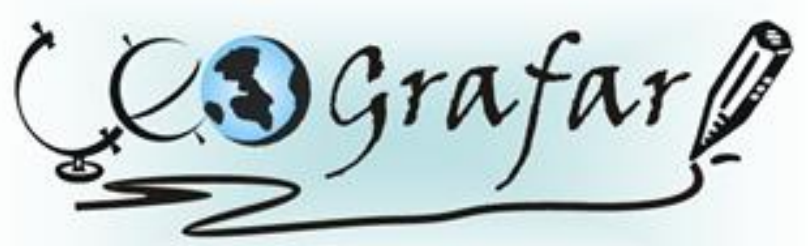

Revista Eletrônica do Programa de Pós-Graduação em Geografla - UFPR

\title{
ENSAIOS SOBRE O MEIO (AMBIENTE): OS SIGNIFICADOS DE NATUREZA POR OLHARES GEOGRÁFICOS
}

\author{
MOISÉS ORTEMAR REHBEIN ${ }^{1}$
}

\begin{abstract}
Resumo: Esse artigo se desenvolve a partir da questão, objeto de estudo: qual o conceito de ambiente (meio, natureza) na Geografia? Essa se reconhece não como uma indagação nova, mas como uma indagação que, acredita-se, move reflexões continuas, dado o caráter dinâmico e balizador de que o conceito goza na Geografia. Estrutura-se este trabalho através de revisões bibliográficas de contemporâneos geógrafos. Apresenta-se e se discute a (des) construção do pensar ambiente, a edificação de novo paradigma ambiental e o que se tem dito, atualmente em voga, como ambiente na geografia; por fim, ensaiam-se concepções possíveis de ambiente. Entende-se o ambiente como ( $\mathrm{re}$ ) conhecimento de gêneses, funções, transfigurações e ou como a materialização de processos geológicos e ou históricos. Trata-se, pois, de um espaço particular que, articulado a outros, faz-se pela (re) produção de dinâmicas no tempo. $O$ ambiente é fixo e fluxo, matéria e energia, são significados para com orgânicos e inorgânicos, sobretudo, dotados de valores, instituídos economicamente, socioculturalmente e/ou politicamente.
\end{abstract}

Palavras-chave: Natureza e Geografia; Meio e Geografia; Ambiente e Geografia.

\section{ESSAYS ON THE ENVIRONMENT: THE MEANINGS OF NATURE FROM A GEOGRAPHIC POINT OF VIEW}

\begin{abstract}
This article focuses on the question, object of study: what is the concept of environment (nature) in Geography? This is not regarded as a new question, but as one which needs constant consideration, because of the relevance and dynamics that the concept presents in Geography. Based on bibliographic reviews of contemporary geographers, the article presents and discusses the (de) construction of the environmental thinking, the development of a new environmental paradigm, and the latest ideas about the environment in Geography. In conclusion, the paper presents possible conceptions of environment, understood as the recognition of geneses, functions, transfigurations and/ or the materialization of geological or historical processes. The environment is a specific space which, articulated with other spaces, results from the (re) production of dynamics in the time. The environment is fixed and flow, matter and energy, it has organic and inorganic meanings with economic, sociocultural and/ or political values.
\end{abstract}

Keywords: Nature and Geography; Environment and Geography

\section{CONSIDERAÇÕES INTRODUTÓRIAS}

Este trabalho resulta de um questionamento sobre os significados de ambiente na Geografia. Eis que, em leituras de cunho geográfico, por vezes, o termo ambiente

\footnotetext{
${ }^{1}$ Doutorando, bolsista do CNPq, orientando do professor Dr. Jurandyr Luciano Sanches Ross no Programa de Pós-Graduação em Geografia Física da USP < moisesgeousp@gmail.com
} 
aparece sucedendo o termo meio e ou como sinônimo de natureza, assim como, por vezes, parece ganhar significado próprio que o dissocia dos demais termos citados. Pois, ora o ambiente remete ao entorno físico e as suas interações químicas e biológicas e, por isso, é natureza, ora requer concepções sociais e, por isso, deixa de ser natureza. Entre outros, o conceito de ambiente é considerado por demais abrangente e sua comum associação a outros termos, possibilitando-Ihe significados diversos, acaba por vulgarizá-lo. Essas são observações daqueles que, no trato da questão ambiental, resistem ao uso da expressão ambiente. Fazem-se também considerações a respeito da redundância semântica quando ambiente é precedido de meio, ou seja, quando se expressa: meio ambiente. Pois sim, a adoção do ambiente como referência de estudo, dado o não consenso de seu entendimento na geografia, expõe leituras que conflitam.

Todavia, para Suertegaray (2000) o ambiente é conceito que, dentre outros, intitula balizador na Geografia. Desse modo, lança-se o desafio de se dissertar a partir da questão: qual o significado de ambiente na Geografia? Essa se reconhece não como uma indagação nova, mas como uma indagação que, acredita-se, move reflexões continuas. Assim sendo, que fique bem claro, não se tem a pretensão de "última palavra". Compartilha-se da idéia de que "os conceitos são significados e estão sempre em movimento" (COELHO, 2006, p. 29).

Estrutura-se este artigo, enquanto reflexão acerca da temática que se põe no parágrafo anterior como indagação, através de revisões bibliográficas de contemporâneos geógrafos. Apresenta-se e se discute a (des) construção do pensar ambiente, a edificação de novo paradigma ambiental e o que se tem dito, atualmente em voga, como ambiente na geografia; por fim, ensaiam-se concepções possíveis de ambiente pela fundamentação teórica edificada.

\section{A (DES) CONSTRUÇÃO DO PENSAR AMBIENTE}

Até meados do século XX, conforme Mendonça (2005), a geografia, outras ciências e a sociedade em geral concebiam o ambiente exclusivamente do ponto de vista naturalista. A abordagem da temática ambiental pela geografia nesse momento, naturalista, pautou-se: “(...) pelo detalhamento das características físicas 
dos lugares, mensurando e catalogando-as, ao mesmo tempo em que procurando explicações para suas dinâmicas e o estabelecimento de leis numa tentativa de sistematização dos conhecimentos apreendidos (...)" (MENDONÇA, 2005, p. 22).

O ambientalismo geográfico de cunho naturalista, que compreendeu o período que vai da origem da geografia como ciência no século XIX até meados do século $\mathrm{XX}$, em linhas gerais, concebeu o meio ambiente dissociado do homem ou de qualquer sociedade humana, focando-se na descrição do quadro natural do planeta, compreendido pelo relevo, clima, vegetação, hidrografia, fauna e flora (MENDONÇA, 2005). Mas essa não é uma visão superada de ambiente na contemporaneidade pela geografia e/ou ramos deste conhecimento.

Dessa forma, com uma abordagem naturalista, parece concebida a noção legal de meio ambiente no Brasil. De acordo com a Lei Federal 6.938 de 31 de agosto de 1981, artigo $3^{\circ}$, parágrafo I, lê-se meio ambiente como: "o conjunto de condições, leis, influências e interações de ordem física, química e biológica, que permite, abriga e rege a vida em todas as suas formas". A concepção legal de meio ambiente, de fato, revela-se significativamente abrangente, todavia, não se vislumbram numa primeira leitura conexões às atividades humanas, não há caráter social explícito na formulação da proposição legal de meio ambiente. Apenas em exercício de abstração, pensando-se em possíveis desdobramentos de significados, entrevemos possibilidades de articulação ao social. "Leis, influências e interações" remetem interpretações cognitivas, respaldadas socioculturalmente. A frase "a vida em todas as suas formas" poderia abrir margens para interpretação do tipo: "a vida em sua forma social", fundamentada cultural e economicamente? De qualquer modo, essa observação/indagação parecem possibilidades outras que, além de uma primeira leitura, resultantes de desdobramentos argumentativos sobre a proposição institucional que define meio ambiente.

Para Gonçalves (1989), em "Os (des) caminhos do meio ambiente", a separação homem-natureza, homem enquanto indivíduo e coletivo que socioculturalmente instituídos, é uma característica efusiva do pensamento que tem dominado o chamado mundo ocidental; cuja matriz filosófica se encontra na Grécia e Roma clássicas. Acrescenta Gonçalves (1989, p.28) que "(...) a afirmação desta 
oposição homem-natureza se deu, no corpo da complexa História do Ocidente, em luta com outras formas de pensamento e práticas sociais".

Outras formas de pensamento talvez herdadas de filósofos da chamada época pré-socrática, pois, na história do mundo ocidental, o modo de concepção da natureza já foi significativamente distinto do concebido nos ditos períodos da história moderna e mesmo contemporânea. Tão distinto em seu possível germe, o modo de concepção da natureza (physis do grego) na época pré-socrática, que leva Bornheim (1985), apud Gonçalves (1989, p. 30 -1), a considerar:

(...) A palavra physis indica aquilo que por si brota, se abre, emerge, o desabrochar que surge de si próprio e se manifesta neste desdobramento, pondo-se manifesto. Trata-se, pois, de um conceito que nada tem de estático, que se caracteriza por uma dinamicidade profunda, genética (...) a physis encontra em si mesma a sua gênese; (...) princípio de tudo aquilo que vem a ser (...) a physis é a totalidade de tudo o que é (...) convém chamar a atenção para um desvio em que facilmente incorre o homem contemporâneo. Posto que a nossa compreensão do conceito de natureza é muito mais estreita e pobre que a grega, o perigo consiste em julgar a physis como se os pré-socráticos a compreendessem a partir daquilo que nós hoje entendemos por natureza (...) para os pré-socráticos, já de saída, o conceito de physis é o mais amplo e radical possível, compreende em si tudo que o existe (...) à physis pertencem o céu e a terra, a pedra, a planta, o animal e o homem, o acontecer humano como obra do homem e dos deuses e, sobretudo, pertencem à physis os próprios deuses. Devido a esta amplidão e radicalidade, a palavra physis designa outra coisa que o nosso conceito de natureza. Vale dizer que, na base do conceito de physis, não está nossa experiência da natureza, pois a physis possibilita ao homem uma experiência totalmente outra que não a que temos face à natureza (...) Pensar o todo real a partir da physis é pensar a partir daquilo que determina a realidade e a totalidade do ente.

Já em Platão e Aristóteles se vislumbra uma relativa marginalização do que 0 céu, a terra, a pedra, a planta e o animal em detrimento da valorização do que é o homem e a idéia. Toma rumo à transformação do significado de physis, de natureza, que aos poucos se edificará de modo desumanizado. Mas, antes de se chegar à oposição homem-natureza, se vislumbram as separações/oposições espírito-matéria e sujeito-objeto. Platão falava que só a idéia era perfeita em oposição à realidade mundana. O cristianismo, numa releitura, irá opor a perfeição de Deus (espírito) à imperfeição do mundo material. Essa leitura própria de Aristóteles e Platão, realizada pela Igreja na Idade Média, faz-se sob o olhar da censura e, assim, limitam-se outras possíveis (re) leituras. Logo, toma vulto a separação espírito- 
matéria. Os cristãos vão afirmar decididamente que "Deus criou o homem à sua imagem e semelhança”. Deus, em letra maiúscula, ganha significado outro que o difundido entre os pré-socráticos. Aliás, com o cristianismo no ocidente, Deus sobe aos céus e, de fora, noutra possível dimensão, passa a agir sobre o mundo imperfeito dos mortais. O homem é, a despeito de ser imagem e semelhança de Deus, dotado de um privilégio que o anima (do grego ânima, alma). Quando o ânimo está a findar, pensamos na morte terrena, temos um momento de separação: alma e corpo, este último, agora desvinculado do espírito, é apenas matéria. A matéria demanda estudos, dado o assombro de pestes que rondam o mundo conhecido. Enquanto matéria o corpo vira um objeto, um possível objeto de estudo frente a um sujeito, o próprio homem, o eu pensante, consciência, espírito ou mente enquanto faculdade cognoscente e princípio fundador do conhecimento. Dessa forma, simplificando-se, toma vulto à separação/oposição sujeito-objeto, isso ocorre especialmente com Descartes ou com a filosofia cartesiana (GONÇALVES, 1989).

Dois aspectos da filosofia cartesiana marcam o pensamento na modernidade: 0 antropocentrismo e o caráter pragmático-utilitarista que o conhecimento adquire. Em síntese, o homem é visto como centro do mundo, o sujeito em oposição ao objeto, à natureza. O homem, então instrumentalizado por métodos científicos, pode avançar pelos mistérios da natureza e, assim, tornar-se senhor e possuidor da natureza, esta agora é um recurso, um meio para se atingir um fim. Toma vulto a separação/oposição homem-natureza. Convém lembrar que tais rumos do pensamento, o antropocentrismo e o caráter pragmático-utilitarista do mesmo, estão vinculados ao Mercantilismo, ao desenvolvimento da técnica, à instituição do Capitalismo e à Revolução Industrial. O século XIX será o do triunfo desse mundo pragmático, com a ciência e a técnica tomando significados fundamentais na vida do homem. A natureza, cada vez mais um objeto a ser possuído e dominado, então é subdividida em física, química, biologia. O homem em economia, sociologia, antropologia, história, psicologia, etc. Pensar o homem e a natureza organicamente ou integralmente se torna, progressivamente, não usual. Mesmo a geografia que, em princípio, não caberia dentro dessa oposição homem-natureza, reproduz, no seu interior, essa dicotomia através da separação entre a geografia humana e a geografia física (GONÇALVES, 1989). 
Os fundadores da geografia, destacando-se Ritter, Ratzel e La Blache, apresentam, ainda que de distintos modos, um objeto de estudo para a geografia focado na relação homem-meio (natureza), mas a geografia desse período tendeu a naturalizar o homem, na medida em que o via como mais um constituinte do espaço geográfico. Interessava à geografia a obra materializada e não as relações sociais, pois, como dizia La Blache: "a geografia é a ciência dos lugares e não dos homens." (SUERTEGARAY, 2000).

Em seu período inicial, referia-se a geografia ao meio (milieu) que, como para Bertrand (1968) conforme Suertegaray (2000), está impregnado de um sentido ecológico. A origem histórica dessa noção de meio (ambiente) está vinculada à biologia, tendo sido introduzida nesta área de conhecimento pela mecânica newtoniana. A partir de Isaac Newton o universo é cientificamente concebido como um sistema. Todavia, não tinha evolução, sempre repetia o mesmo movimento, tal como um relógio que marca o tempo dos outros seres, mas não o seu próprio tempo (GONÇALVES, 1989).

Em seu desenvolvimento histórico, o conceito de ambiente assume a concepção de sistema: de unidade de diversas manifestações entre si relacionadas, a partir dos termos em que o estruturalismo o redefiniu como organismo (ALIATRA \& SILVESTRI, 1994; apud SUERTEGARAY, 2000). Mas o organismo evolui, como demonstrou Charles Darwin, e sob o resplandecer das idéias de sistema, com o desenvolvimento da etologia, ciência que estuda os hábitos dos animais e das acomodações às condições do ambiente, e de uma série de descobertas científicas, provenientes principalmente da biologia, lança-se à luz a concepção de ecossistema. Este, perante o significado de natureza, ganha relevante dimensão, tal qual ao encontro de associação ou mesmo suplantação. O ecossistema, para além de um organismo, guardado o seu caráter organizador, é uma unidade complexa sistema. O ecossistema é, sobretudo, o biótopo - o meio geofísico - e a biocenose conjunto das interações entre seres vivos de todas as espécies que povoam este biótipo (GONÇALVES, 1989).

Nessa perspectiva ecossistêmica, o ambiente é lido como algo externo ao homem, cuja preocupação seria estudar o funcionamento dos sistemas naturais. Ou incluir o homem, neste caso, "em uma única esfera cuja chave principal de leitura 
está constituída por processos naturais" (ALIATA \& SILVESTRI, 1994; apud SUERTEGARAY, 2000, p. 27).

Muitos geógrafos viram no método sistêmico uma das possibilidades de entender a natureza de forma integrada e atribuíram à natureza uma dimensão sistêmica. Para estes, a natureza é sistêmica. A Teoria de Sistemas, aprimorada, sobretudo, do ponto de vista da modelização e quantificação dos elementos arrolados na abordagem geográfica, foi defendida por significativo número de pesquisadores que se concentravam no estudo do ambiente sob a ótica da geografia. $\mathrm{O}$ desenvolvimento de metodologias próprias para a referida abordagem apareceu como primeira necessidade e, desta maneira, alguns geógrafos desenvolveram o conceito de geossistema proposto no início dos anos 60 por Sotchava (MENDONÇA, 2005; SUERTEGARARY, 2008).

Decorrem destas observações diferentes manifestações: a natureza não é sistêmica, ela pode ser analisada sistemicamente, o sistemismo não é uma teoria interpretativa da natureza, constitui um caminho analítico, um método. O sistemismo, no âmbito da geografia, não fugiu da compartimentação. Há controvérsias em relação ao conceito de geossistema, ora compreendido como sistema natural, ora concebido como sistema integrativo da natureza com a sociedade (SUERTEGARAY, 2008).

De qualquer forma, a abordagem sistêmica tem sido um caminho significativamente utilizado por geógrafos no desenvolvimento de seus trabalhos. Há que se lastimar, assim o faz Mendonça (2005), quando do esquecimento/descaso, através do uso desta abordagem na geografia, da busca pela compreensão das relações sociais enquanto componente das diversas paisagens.

A concepção de meio, ambiente ou natureza ganha outros significados na geografia, sobretudo por sua aproximação com a sociologia, a partir do materialismo histórico. Nesse momento, parte da geografia passa a preocupar-se com o espaço geográfico, entendendo-o como resultado das formas de produção. Dessa maneira, a geografia concebe a relação homem-natureza, ou melhor, sociedade-natureza sob a ótica da apropriação, concebendo a natureza como recurso à produção. Toma vulto a expressão meio. Esse debate, por vezes embate/combate, redimensionou para mais, ao mesmo tempo em que aprofundou discussões socioeconômicas na 
edificação do espaço geográfico, mas restringiu possibilidades analíticas da natureza em si, no seu corpo referencial (SUERTEGARAY, 2000).

O sub-ramo geografia humana foi o carro-chefe desta geografia, que se intitulou geografia marxista - geografia radical. A forte proximidade com a sociologia, história e economia política foi notória e comprometedora, quando se observa um total esquecimento da abordagem do suporte físico-territorial sobre o qual são processadas as atividades sociais (MENDONÇA, 2005).

(...) O marxismo é um método restrito às ciências sociais, onde conhece uma ampla difusão. Alfred Schimidt mostrou, em interessante estudo, a inexistência de uma perspectiva ontológica a respeito da Natureza no interior da obra de Marx. Nesta, os fenômenos naturais nunca são enfocados em seu movimento intrínseco, porém abordados enquanto recursos para vida humana. Assim, é uma "natureza para o homem" que sempre está em foco nas considerações marxianas. Notadamente, ele discute as condições naturais em seu desenvolvimento com os processos produtivos como "pressuposto geral de toda a produção". Segundo Marx, a matéria ambiental pré-existe ao trabalho humano, sendo nesse sentido o seu objeto universal (MORAES, 1990 Apud MENDONÇA, 2005, p. 57-8).

Observa-se que natureza sempre foi um conceito muito próximo da geografia, embora, lembra Suertegaray (2008), pouco discutido em si. A geografia, por longa data, não se preocupou em entender o significado dado à natureza em suas análises. Consideraram-na, como também em outras áreas do conhecimento, como algo dado, objetivo e externo.

O entendimento fragmentado da realidade que caracterizou a construção do "pensamento na modernidade", apresentado em Latour (1994) e mencionado por Suertegaray (2008, p. 43) como "purificação do conhecimento", induziu a "separação total dos humanos e dos não-humanos e, por simultaneamente anular esta separação, tornou os modernos invencíveis". É resultado da constituição da Modernidade a idéia de natureza enquanto externalidade ao humano. É este o significado cultural, econômico e político circunscrito a natureza nesta construção. Também, oportuno foi "(...) introduziram-se milhares de objetos naturais no corpo social dotando-o da solidez das coisas naturais". Neste sentido, "a leitura de nossa base filosófica-científica se inscreve na necessidade atual de decifrar um mundo 
extremamente complexo, onde sob muitos aspectos a natureza não é natural" (SUERTEGARAY, 2008, p. 06).

Em nossa sociedade (ocidental), contemporaneamente e de forma reinante, materializa-se no imaginário a natureza como algo que se contrapõe à cultura. $\mathrm{A}$ cultura representa aquilo que, por superioridade, conseguiu controlar a natureza, um sempre objeto a ser dominado por um sujeito, o homem. Mas o materialismo histórico faz bem em lembrar: nem todos os homens são proprietários da natureza, são alguns poucos homens que dela verdadeiramente se apropriam. Neste sentido, contempla-nos Gonçalves (1989): esquece-se na visão tradicional de naturezaobjeto versus homem-sujeito, que a palavra sujeito abarca significado que não apenas substantivo, mas também adjetivo: ser sujeito é ser ativo, dono do seu destino, mas também é ser ou estar sujeito, submetido, a determinadas circunstâncias.

Também materializados no imaginário, do chamado mundo ocidental, estão duas outras vertentes de pensamentos acerca de natureza:

(...) ou vemos a natureza como algo hostil, lugar da luta de todos contra todos, da chamada lei da selva, ou vemos a natureza como harmonia e bondade. [...] A primeira vertente afirma o antropocentrismo e a segunda 0 naturalismo. Homem e natureza caem um fora do outro (GONÇALVES, 1989, p. 62).

\section{NOVOS PARADIGMAS AMBIENTAIS}

Como já mencionado, a extrema fragmentação do conhecimento consagrou a separação entre o homem e a natureza, sobretudo a partir do século XIX. As influências de Descartes, também Galileu, Leibniz e, particularmente, de Isaac Newton contribuíram para formar o imaginário iluminista, fundado na idéia de physis ordenada tal e qual um relógio, cujos ponteiros fazem sempre os mesmos movimentos. O universo newtoniano é "relojoeiro", mecanicista, sincronizado e não diacronizado. As concepções teórico-metodológicas científicas da época, socialmente instituídas, privilegiaram nas suas análises o sincrônico ao diacrônico. $O$ Funcionalismo, o Estruturalismo e a Teoria Geral dos Sistemas - que privilegiam o estudo do modo como um determinado fenômeno (sistema) atua, em detrimento da 
análise do modo como se constituíram as condições do seu funcionamento ganham uma solidez mais aparente que real. Isso porque, embora a realidade apareça à primeira vista como funcional, dando a impressão de que tais pressupostos são capazes de dar conta teoricamente da realidade cotidiana, logo aparece uma greve, um conflito e múltiplas tensões que sinalizam a existência de contradições no interior da aparente funcionalidade do sistema (GONÇALVES, 1989).

Toma-se como exemplo o ecossistema. Numa primeira leitura, a regularidade e a invariância se sobressaem, tal como num relógio, em cada ecossistema. Fazem-se evidentes as concepções de equilíbrio e de harmonia, as quais, em significativos níveis de reflexões, inegavelmente demandas legítimas. Mas há também de se questionar e relativizar tais concepções (GONÇALVES, 1989).

\begin{abstract}
(...) A ordem física prolonga-se na ordem viva, ela própria regida por "programas genéticos", fabricadores de invariância e de repetição; assim, a natureza aparece como permanência, regularidades, ciclos. E, no entanto, quando olhamos, quer a muito longo termo quer de perto, esta ordem subitamente vacila e se fende. À escala de centenas de milhares de anos o subsolo fende-se e se desloca; a crosta terrestre enruga-se, subleve-se, abate-se, os continentes derivam; as águas inundam as terras que emergem da água; as florestas tropicais e as calotas glaciais avançam ou recuam; as erosões cavam, nivelam, pulverizam. Olhando mais de perto e a curto tempo, vemos uma confusão de seres unicelulares e de animálculos; uma trapalhada e uma desordem de plantas misturadas, entreparasitas através das florestas (...) insetos agitados por movimentos desordenados (...) por todo lado, uma autofagia permanente da vida comendo a vida, uma luta feroz de todos contra todos (...) Como conjugar estas duas visões que, até aqui, sempre se repeliram uma à outra, uma feita de ordem e de harmonia, a outra de desordens e de luta? Estas duas visões, contrárias, são ambas per si verdadeiras (MORIN, [s/d] apud GONÇALVES, 1989, p. $64)$.
\end{abstract}

As significativas transformações pelas quais passou a Terra, com a tectônica de placas e a formação/destruição do relevo, com as mudanças climáticas e os avanços e recuos das calotas polares, da água do mar, etc. contam uma história em que se ressaltam as aptidões dos ecossistemas à construção de novas estabilidades, em detrimento à estabilidade dos ecossistemas em estado de clímax (estado de equilíbrio para o qual tendem todos os ecossistemas e no qual podem se manter indefinidamente, desde que nenhum acidente externo se sobreponha aos ciclos que os constituíram). É em contexto de construção versus destruição e vice- 
versa que os ecossistemas apresentam harmonia. A eco-evolução registra inúmeras mutações ecológicas, isto é, reestruturações novas sob o efeito de perturbações a longo e curto prazo (GONÇALVES, 1989).

[...] Cada ecossistema "é organização espontânea que, baseado em suportes geofísicos deterministas e em seres geneticamente determinantes, faz-se a si mesmo, sem ser incitado ou obrigado por um programa, sem dispor de uma memória autônoma e duma computação própria, sem ser organizado e ordenado por um aparelho de controle, regulação, decisão, governo" (MORIN, [s/d] apud GONÇALVES, 1989, p. 64).

Assim, a espontaneidade é eco-organizadora. Cada ecossistema é um todo que se organiza a partir das interações dos seres que o constituem. Portanto, o todo, o ecossistema, só existe pelas interações entre as partes e são essas complexas interações que o constituem. Tais interações, que se operam na biocenose, são ao mesmo tempo complementares - associações, sociedades, simbioses, mutualismos; - concorrenciais - competição, rivalidades; e antagônicas - parasitismos, fagias, predações. O caráter organizador daquilo que é complementar parece se opor ao caráter desorganizador e destruidor daquilo que é concorrencial e parasita, mas esta oposição é ambígua e relativa, pois antagonismo e complementariedade não excluem um ao outro (MORIN, [s/d] apud GONÇALVES, 1989).

Essas considerações nos permitem vislumbrar outra concepção de natureza, para além daquelas enraizadas em nossa sociedade: ou a natureza é o lugar onde todos lutam contra todos, onde impera a lei da selva ou a natureza é o lugar da bondade e da harmonia. Pois a natureza não é nem um caos nem tampouco um cosmos perfeitamente ordenado e organizado. Ela é um caosmo (MORIN, [s/d] apud GONÇALVES, 1989).

Assim, na busca pela melhor compreensão da natureza, do meio ou ambiente, afirma-nos Gonçalves (1989), faz-se necessário romper com o pensamento simplificador e excludente e afirmar a complexidade, da qual nos fala Morin (2005). Da mesma forma, para Mendonça (2005, p. 70) o tratamento da temática ambiental é atividade complexa, tanto do ponto de vista teórico como, sobretudo, do ponto de vista da práxis: 
Somente ações desenvolvidas do ponto de vista da holisticidade da temática (ambiental) é que conseguem apresentar resultados satisfatórios no tocante às tentativas de melhor recuperação e preservação de ambientes degradados locais, regionais ou planetário.

Ainda nesta linha de raciocínio, ou seja, no que diz respeito à concepção da temática ambiental, a contribuição do sociólogo Herbert de Souza, enunciada em Mendonça (2005), aponta para a necessidade de uma compreensão atual da referida temática baseada nas proeminentes disparidades socioeconômicas que caracterizam as diversas realidades entre os países, no tocante ao seu desenvolvimento.

[...] nos países desenvolvidos o meio ambiente (environment) é compreendido como algo em prol de cuja preservação e conservação se luta, ao mesmo tempo em que pelo seu tombamento e buscando defender santuários ecológicos. A preocupação com espécies em extinção é muito grande e o homem, aparentemente, nem sempre é compreendido como elemento do meio. Este ponto de vista é, porém, completamente incompatível com a realidade dos países classificados de terceiromundistas. Neles, as condições de vida da população humana, bem como sua qualidade, encontram-se completamente degradadas. É preciso, primeiramente, resgatar o mínimo necessário à sobrevivência de cada um e a condição de cidadania, absurdamente seqüestrada por uma minoria hereditariamente no poder. Falar de meio ambiente em tal contexto não tem nenhuma ressonância (MENDONÇA, 2005, p. 70-1).

Esta concepção de meio ambiente aponta principalmente para o fato de que no Brasil, por exemplo, falar de meio ambiente significa, antes de tudo, lutar para o equacionamento de graves problemas sociais que tão marcadamente caracterizam o espaço geográfico nacional. A crise ambiental que dos últimos séculos emerge não pode ser compreendida, tampouco resolvida, segundo perspectivas que dissociam 0 natural e o social (GONÇALVES, 1989; MENDONÇA, 2001, 2005). "[...] Se permanecermos insistindo no estudo da natureza (em seu conjunto ou em seus fragmentos) em separado da sociedade, muito provavelmente, teremos respostas parciais para problemas complexos" (SUERTEGARAY, 2008, p.12).

Neste sentido, pode-se observar que a noção de Ambiente tem agregado, paulatinamente, a dimensão social. Essa transformação do conceito de ambiente é resumida nas colocações de Bailly e Ferras (1997); citados em Mendonça (2001, p. 116): 
Em 1917, o meio ambiente, é para uma planta o resultante de todos os fatores externos que agem sobre ela. Em 1944, para um organismo, a soma total efetiva de fatores, aos quais um organismo responde. Em 1964, Harant e Jarry propõem: o conjunto de fatores bióticos (vivos) ou abióticos (físicoquímico) do hábitat. Em 1971, segundo Ternisien: conjunto, num momento dado, dos agentes físicos, químicos e biológicos e dos fatores sociais suscetíveis de ter um efeito direto ou indireto, imediato ou a termo, sobre os seres vivos e as atividades humanas.

Observa-se na evolução do conceito de ambiente um envolvimento crescente das atividades humanas. No entanto, para Mendonça (2001), ainda assim, o termo ambiente parece não conseguir se desvincular da sua gênese fortemente marcada por princípios naturalistas. Pois, acredita o autor que se tenha gerado "uma concepção cultural do meio ambiente que exclui a sociedade da condição de componente e a inclui como agente/fator" (MENDONÇA, 2001, p. 05).

[...] o homem socialmente organizado parece se constituir mais num fator que num elemento do ambiente. De maneira geral, e observando-se tanto o senso comum como o debate intra e extra-academia, a impressão geral que se tem é de que a abordagem do meio ambiente está diretamente relacionada à natureza, como se existisse um a priori determinante traduzido numa hierarquização dos elementos componentes do real, onde aqueles atinentes ao quadro natural estão hierarquicamente em posição mais importante e sem os quais não haveria a possibilidade da compreensão ambiental da realidade (MENDONÇA, 2001, p. 117).

Acrescer nas discussões ambientais a perspectiva social, econômica, política e cultural, soa como um desafio para toda uma geração de intelectuais, cientistas e ambientalistas que se encontra vinculada a tais discussões no presente. Diante de tão importante desafio na atualidade, Mendonça (2001) observa uma forte tendência à utilização, de forma ampla, do termo "socioambiental".

A questão ambiental institui novo paradigma, em que natureza e cultura não caiam uma fora da outra. Isso não significa reduzir o homem ao reino da natureza, da animalidade, mas sim, significa reconhecer as especificidades naturais do homem: o homem, por natureza, produz cultura. A cultura humana não sai da natureza, ao contrário, é uma das suas qualidades (GONÇALVES, 1989). “(...) O homem é a um só tempo obra e artífice do meio que o rodeia, o qual lhe dá sustento material e a oportunidade de desenvolver-se intelectual, moral, social e espiritualmente", declarações essas proferidas na PRIMEIRA CONFERÊNCIA 
MUNDIAL DO DESENVOLVIMENTO E MEIO AMBIENTE, (Estocolmo, 1972) e citadas em MENDONÇA (2005, p. 48).

Portanto, cultura não exclui natureza, desenvolve-se no interior dela, processando sínteses, socialmente instituídas, de matéria e energia, formas de mediação entre homens e outros orgânicos e inorgânicos. Os homens criam normas, regras, instituições, etc., não para evitar cair no estado de natureza, mas desenvolvendo a sua própria natureza, em função de estímulos advindos do meio ambiente, que incluem as relações dos homens entre si. Toda cultura elabora os seus conceitos, inclusive o de natureza, ao mesmo tempo em que institui suas relações sociais (GONÇALVES, 1989).

[...] Homem e Natureza são concebidos como parte de um mesmo processo de constituição de diferenças. O homem é a natureza que toma consciência de si própria e esta é uma descoberta verdadeiramente revolucionária numa sociedade que disso se esqueceu ao se colocar o projeto de dominação da natureza (GONÇALVES, 1989, p. 09).

Também para Latour (1994), apud Suertegaray (2008, p. 38) "natureza e sociedade não são dois pólos distintos, mas antes uma mesma produção de sociedades - naturezas, de coletivos.

A cultura é criação dos homens e resulta de processos, observados na história, marcados por inúmeras tensões e conflitos, cujas motivações são instituir possibilidades outras. Se a relação com a natureza e dos homens entre si, instituída por nossa sociedade-cultura, não agrada, tem-se que contorná-la, superá-la, através de reflexões e ações mais democráticas e sustentáveis. É fundamental tomar consciência de que o conceito de natureza e de homem instituído, que se apresenta como condição, não é mais nem menos natural que qualquer outro, é uma "opção" socioculturalmente moldada. "[...] Não existem palavras naturais para falar de natureza. As palavras são criadas e instituídas em contextos sociais específicos e também por este modo o conceito de natureza não é natural" (GONÇALVES, 1989, p. 63).

Há necessidade de se pensar o conceito de natureza adotado e avaliar sua pertinência em relação aos problemas e/ou aos objetos atuais. A sociedade 
contemporânea, diante de suas necessidades, ultrapassou a dimensão do conhecimento nas suas especializações/purificações. Neste sentido, observa-se que a geografia é palco de um longo conflito que se revela ora nas propostas de especialização ora nas propostas de conjunção. Teoricamente a geografia foi sempre conjuntiva e para alguns também 0 foi na prática científica (SUERTEGARAY, 2008).

\title{
O QUE SE TEM DITO NA GEOGRAFIA DO AMBIENTE
}

\begin{abstract}
A partir da Conferência Internacional sobre Meio Ambiente, que deu lugar ao que se costumou chamar de "Conferência do Rio-92", à semelhança da "Conferência de Estocolmo de 1972", difundiu-se o conceito de "desenvolvimento sustentável", que certamente redefiniu os rumos de uma abordagem ambientalista até então extremamente ecológica/ biológica e de uma visão absolutamente preservacionista para uma abertura mais humanista e do entendimento de que a humanidade é uma parte importante, senão a mais importante, do meio ambiente. Em função disso, acentuou-se a relevância do entendimento das relações sociedadenatureza, tanto pelo lado de suas contradições como pelo dos aspectos de suas inter-relações de dependências e funcionalidades (ROSS, 2006, p. 19 e 20).
\end{abstract}

"O ambiente não é visto apenas como o meio físico e biótico, mas inclui também o sócio-econômico" (ROSS, 2007, p. 18). "O meio ambiente atualmente em voga é propalado na perspectiva que engloba o meio natural e o social" (MENDONÇA, 2005, p. 23).

Baseando-se em postulados de Chorley \& Kennedy (1971), tentando formalizar uma noção de ambiente, Silva (1995, p. 348) define o termo como:

(...) um conjunto estruturado sobre uma determinada localização, que tem uma extensão determinável e representa uma síntese da atuação de uma variada gama de fatores ambientais - naturais e socioeconômicos correlacionados casual ou aleatoriamente para produzi-lo.

Acredita Veyret (1999), citado em Mendonça (2001, p. 117), que contemporaneamente: “(...) para um geógrafo, a noção de meio ambiente (...) designa as relações de interdependência que existem entre o homem, as 
sociedades e os componentes físicos, químicos, bióticos do meio e integra também seus aspectos econômicos, sociais e culturais".

Entende Corrêa (2005), ainda que mencione segundo a visão da geografia humana, o meio ambiente como o conjunto de três aspectos interligados: fixos, fluxos e o homem. Trata-se o meio ambiente do resultado material da ação humana (objetos materiais fixos), da natureza transformada pelo trabalho social, da segunda natureza, da transformação da natureza primitiva sob égide da ação humana historicamente contextualizada, que incorpora os conflitos sociais de cada período e o desenvolvimento de forças produtivas. Os fixos, também o são enquanto produtos sociais, produtos de uma ruptura de um dado equilíbrio ecológico pela ação transformadora do homem. $\mathrm{O}$ ambiente também engloba os diferentes fluxos que interconectam os diferentes objetos criados pela ação humana. O meio ambiente agrega, assim, os fixos e os fluxos. Mas há mais. O meio ambiente não pode deixar de incluir o homem, mas um homem qualificado pelas suas relações sociais, sua cultura, seu ideário, mitos, símbolos, utopias e conflitos, um homem que, simultaneamente, é produtor e usuário do meio ambiente, mas também por meio dele, algoz e vítima. Assim explicitado, acredita Corrêa (2005), o conceito de meio ambiente se confunde com o de meio geográfico, estando muito além dos limites das ciências da natureza.

$\mathrm{Na}$ discussão de espaço geográfico enquanto uno e múltiplo, entende Suertegaray (2000) o ambiente como um conceito, dentre outros (paisagem, lugar e território), que denomina como balizador da geografia, que expressa possibilidades analíticas da geografia relativas à questão ambiental. Em outras palavras, o conceito de ambiente expressa uma possibilidade de leitura do espaço geográfico ou, dessa forma, um caminho metodológico. Ao tratar do espaço geográfico, tomando como referência o conceito de Milton Santos (1997), Suertegaray (2000) traz à luz reflexões sobre a estruturação de ambiente, sobre um significado de natureza que vislumbra na contemporaneidade.

O espaço geográfico [...] é formado por um conjunto indissociável, solidário e também contraditório, de sistemas de objetos e sistemas de ações, não considerados isoladamente, mas como um quadro único no qual a história se dá. No começo era a natureza selvagem, formada por objetos naturais, que ao longo da história vão sendo substituídos por objetos fabricados, 
objetos técnicos, mecanizados e, depois cibernéticos, fazendo com que a natureza artificial tenda a funcionar como uma máquina (SANTOS, 1997 apud SUERTEGARAY, 2000, p. 15).

Este conceito expressa articulação entre sociedade e natureza. Trata-se, nesse caso, de uma concepção de natureza denominada natureza artificial, tecnificada ou, ainda, instrumental, decorrente do período "Técnico-Científico Informacional". A técnica no seu estágio atual permite a intervenção, não só nas formas, como nos processos naturais. Os depósitos tecnogênicos podem bem ilustrar essa afirmação. Tratar-se-ia a natureza, nessa circunstância, propõe Suertegaray (2000), não mais como uma dimensão de interface com a sociedade, mas como uma dimensão de transmutação/transfiguração. Uma natureza possuída pelo homem/ transfigura-se, adquire outra dimensão. "(...) transfiguração é a passagem de uma figura para outra. Além disso, ela é, de certa maneira, mesmo que mínima, próxima da possessão" (MAFFESOLI, 1995 apud SUERTEGARAY, 2000, p. 30). Cabe registrar que o uso do termo transfiguração já tinha sido adotado por Reclus, para se referir à dominação da natureza pelo homem, na sua obra $L^{\prime}$ homme et la Terre comentada por Béatrice Giblin (SUERTEGARAY, 2008).

Voltando-se à relação espaço geográfico versus ambiente, diz-nos Suertegaray (2000) que, ao se conceber o espaço geográfico como um todo uno e múltiplo, temos de concebê-lo aberto a múltiplas conexões que se expressam através de diferentes conceitos, dentre eles, cita-se o de ambiente. Assim, pode-se dizer que 0 ambiente enfatiza uma dimensão da complexidade organizacional do espaço geográfico, como concebe a autora, pela transfiguração da natureza.

De certa forma, essas premissas são sustentadas por Coelho (2006, p. 23) ao afirmar que:

[...] o ambiente ou meio ambiente é social e historicamente construído. Sua construção se faz no processo de interação contínua entre uma sociedade em movimento e um espaço físico particular que se modifica permanentemente. O ambiente é passivo e ativo. É, ao mesmo tempo, suporte geofísico, condicionado e condicionante de movimento, transformador da vida social. Ao ser modificado, torna-se condição para novas mudanças, modificando, assim, a sociedade. 
Todavia, para Suertegaray (2000), os geógrafos na atualidade compartilham de conceitos diferentes de ambiente. Numa perspectiva naturalista/ naturalizante, ainda se auxiliam de conceitos que não dimensionam a tensão sob a qual se originam os impactos. Mas acredita a autora que esta não tem sido a regra. Considera-se que a geografia tem pensado o ambiente com a inclusão do homem, sobretudo, como um ser social produto e produtor de várias tensões ambientais e, portanto, não como ser naturalizado.

\section{CONCLUSÕES}

Meio, ambiente ou natureza possuem significados, como outros conceitos, socioculturalmente instituídos. As crises ambientais que emergem impõem reflexões acerca desses significados, que, até então, evocavam a separação sociedadenatureza, pois assim construídos ou, pela visão de outros, desconstruídos. $\mathrm{Na}$ geografia, embora também pareça que em outras ciências e em partes da sociedade, a concepção da relação sociedade-natureza têm se feito outra que não mais pela eminência disjuntiva. Há buscas pela edificação de conhecimentos mais próximos da integralidade, por viés de pensamentos que reconhecem a complexidade no desenvolver de suas pesquisas.

As considerações apresentadas sobre o ambiente permitem o reconhecer como um conceito abrangente e por isso dotado de aplicações relativas. $O$ conceito de ambiente é flexível. Essas observações, para alguns, soam negativas. Todavia, tais observações remetem à possibilidade de múltiplas articulações teóricometodológicas que podem nos aproximar da complexidade organizacional do espaço geográfico.

Pelas considerações apresentadas, ensaiam-se concepções possíveis de ambiente: um meio, que inteiro, feito de partes na estruturação de um todo. $O$ ambiente é acepção de processos evidentes, não evidentes, relacionais e de naturezas diversas, por vezes antagônicas e ainda assim complementares. O ambiente é o reconhecimento de gêneses, funções, transformações, transfigurações e materializa a história das causas, num espaço particular que, articulado a outros, (re) produz dinâmicas, inerentes ou não, no tempo. O ambiente é fixo e fluxo, 
matéria e energia, movimentos, são significados para com orgânicos e inorgânicos, sobretudo, dotados de valores instituídos economicamente, socioculturalmente e ou politicamente.

\section{BIBLIOGRAFIA}

ALIATA, F. \& SILVESTRI, G. El paisage en el arte y las ciências humanas. Buenos Aires: Centro Editor de America Latina S. A., 1994.

BAILLY, A.; FERRAS, R.. Éléments d'épistémologie de la géographie. Paris: Armand Colin, 1997.

BRASIL. Lei Federal № 6.938 de 31 de agosto de 1981. Dispõe sobre a Política Nacional do Meio Ambiente, seus fins e mecanismos de formulação e aplicação, e dá outras providências. Disponível em: <http://www.planalto.gov.br/ccivil_03/Leis/L6938.htm>. Acesso em: 04 jul. 2008.

BORNHEIM, G. Os Filósofos Pré-Socráticos. São Paulo: Cultrix, 1985.

COELHO, M. C. N. Impactos ambientais em áreas urbanas - teorias, conceitos e métodos de pesquisa. In: CUNHA, S. B.; GUERRA, A. J. T. (Orgs.). Impactos ambientais urbanos no Brasil. Rio de Janeiro: Bertrand Brasil, 2001. p. 19-45.

CORRÊA, L. R. Meio ambiente e a metrópole. In: CORRÊA, L. R. Trajetórias geográficas. 3.ed. Rio de Janeiro: Bertrand Brasil, 2005. p. 153-70.

FRAISOLI, C. Capítulo 1- A valorização do espaço; Capítulo 2 - A produção do meio ambiente urbano. In: Valorização do espaço e fragilidade ambiental: o caso da construção do meio ambiente urbano da bacia do córrego Santo Antônio, Mogi Mirim - SP (DISSERTAÇÃO). PPG em Geografia. Instituto de Geociências. Universidade Estadual de Campinas/ UNICAMP. Campinas/ SP. 2005. p. 15-59.

FUJIMOTO, N. S. V. M. Análise ambiental urbana na área metropolitana de Porto Alegre/RS: sub-bacia hidrográfica do Arroio Dilúvio. 2001. 236p. (DOUTORADO) Programa de Pós-Graduação em Geografia. Faculdade de Filosofia e Ciências Humanas/USP. São Paulo, 2001.

GONÇALVES, C. W. P. Os (des) caminhos do meio ambiente. São Paulo: Contexto, 1989.

Formação socioespacial e questão ambiental no Brasil. In: BECKER, B. K. et. al. (orgs.). Geografia e meio ambiente no Brasil. São Paulo/Rio de Janeiro: HUCITEC, 1995. p. 309-33.

GUERRA, A. T.; GUERRA, A. J. T. Novo dicionário geológico-geomorfológico. 5.ed. Rio de Janeiro: Bertrand Brasil, 2006. p. 40 e p. 419. 
LATOUR, B. Jamais fomos Modernos. Tradução de Carlos Irineu da Costa. Rio de Janeiro: Editora 34, 1994.

MAFFESOLI, M. A. Contemplação do mundo. Porto Alegre: Artes e Ofícios/ Hucitec, 1995.

MENDONÇA, F. Geografia física: ciência humana? 3.ed. São Paulo: Contexto, 1992.

Geografia e meio ambiente. 8.ed. São Paulo: Contexto, 2005.

Geografia socioambiental. Terra Livre. São Paulo: AGB, n. 16, $1^{\circ}$ semestre/ 2001. p. 139-58.

MORAES, A. C. R.. Bases Epistemológicas da Questão Ambiental: O Método. Orientação. São Paulo, IGEO/ DGEO/ USP, 1990.

MORIN, E. O método I: a natureza da natureza. Publicações Europa-América, Portugal, s/d.

O método II: A vida da vida. Publicações Europa-América, Portugal, s/d. Introdução ao pensamento complexo. 3.ed. Porto Alegre: Sulina, 2007.

REHBEIN, M. O.; FUJIMOTO, N. S. V. M. Análise ambiental urbana: Vila Augusta/Viamão/ RS. Boletim Gaúcho de Geografia. Porto Alegre: AGB/PA, n, 33, p. 215-32, 2007.

ROSS, J. L. S. Análise empírica da fragilidade dos ambientes naturais e antropizados. Revista do Departamento de Geografia, n. 8, FFLCH/USP, São Paulo, 1994. p. 63-74.

Ecogeografia do Brasil: subsídios para planejamento ambiental. São Paulo: Oficina de Textos, 2006. 208 p.

2007

Geomorfologia: ambiente e planejamento. 8.ed. São Paulo: Contexto,

Geomorfologia aplicada aos Eias-Rimas. In: GUERRA, A. J. T.; CUNHA, S. B. Geomorfologia e meio ambiente. Rio de Janeiro: Bertrand Brasil, 1996. p. 291336.

SANTOS, M. A natureza do espaço. Técnica e tempo, razão e emoção. $2^{\circ}$ Ed. São Paulo: Hucitec, 1997.

SILVA, J. X. A pesquisa ambiental no Brasil: uma visão crítica. In: BECKER, B. K. et. al. (orgs.). Geografia e meio ambiente no Brasil. São Paulo/Rio de Janeiro: HUCITEC, 1995. p. 346-70.

SUERTEGARAY, D. M. A. Espaço geográfico uno e múltiplo. In: SUERTEGARAY, D. M. A.; BASSO, L. A.; VERDUM, R. (Orgs.). Ambiente e lugar no urbano - a grande Porto Alegre. Porto Alegre: UFRGS, 2000. p. 13-34.

Geografia física e geomorfologia: temas para debate (Mesa redonda - 
Epistemologia da Geomorfologia). In: ANAIS DO VII SIMPÓSIO NACIONAL DE GEOMORFOLOGIA - SINAGEO - E II ENCONTRO LATINO-AMERICANO DE GEOMORFOLOGIA - DINÂMICA E DIVERSIDADE DE PAISAGENS. Instituto de Geociências, Universidade Federal de Minas Gerais: UFMG. Belo Horizonte, ago. de 2008.

VEYRET, Y. Geo-environnement. Paris: Sedes, 1999.

(Recebido em fevereiro/2010. Aceito em maio/2010) 